\title{
A CASE OF HEMIPLEGIA,
}

\author{
ASSOCIATED WITH GREAT HYPERTKOPHY OF THE HEART, AND \\ TERMINATING BY RUPTURE OF THE AORTA, \\ PRODUCING. DISSECTING ANEURISM.
}

BY JAMES RISDON BENNETT, M.D.,

FELLOW OF THE ROYAL COLLEGE OF PHYSICIANS, AND ASSISTANT-PHYSICIAN TO ST. THOMAS's HOSPITAL.

Communicated by FREDERICK LE GROS CLARK, Esq.

Received May 24th.-Read June 26th, 1849.

Jонn Spinks, a shoemaker, æt. 52, was admitted into St. Thomas's Hospital, under the care of Dr. Bennett, on the 27th of February, 1849. He is a thick-set, somewhat muscular, well-nourished man, of rather above the middle stature. He states that he has always been temperate, and that, notwithstanding his sedentary employment, he has not suffered from constipation, or any particular dyspeptic symptoms, but has always enjoyed very good health till within the last few months. For five or six months past; however, he has experienced more or less palpitation of his heart, but this appears to have been the only symptom of cardiac disease that has been noticed.

For three months past, he has had more or less of headache, dimness of vision, and vertigo. Fourteen days ago, he awoke in the night with loss of speech and power of voluntary motions of the right side. He had, however, manifested some hesitancy of speech before retiring to bed. His intelligence was not affected, and the sensation of the right side but slightly impaired.

He has now, February 28th, considerable difficulty in speaking, and his articulation is very indistinct. There is no manifest impairment of his intellect, and, although he has not entirely recovered either the sensation or power of motion of the right side, he walks without much dragging 
of the leg, and complains only of some numbness of the fingers. The tongue, which is strongly protruded to the right side, is slightly furred and coated. There is no drawing of the mouth when at rest, but, on directing him forcibly to retract the mouth, it is evident that he has less power on the right than on the left side. He has equal power of winking with both eyes. His appetite is good; the bowels rather sluggish. He complains of giddiness and uncomfortable feeling in the head, but has no headache.

On exertion he has a certain amount of dyspncea, and occasionally a catching of the breath, of a spasmodic character. There is greatly increased impulse of the heart, with extended dulness on percussion over the cardiac region. A slight diastolic bruit is heard below, and a little to the right of the nipple, and there only. Pulse 84, rather full and vibrating. Throughout the chest generally the respiratory and percussion-sounds are natural. There is no œdema of the extremities, nor does the countenance indicate any obstruction to the pulmonary circulation.

He was ordered a jalap and calomel purge to take immediately, and to be cupped over the cardiac region to $\zeta$ viij; and afterwards a pill, containing blue pill and rhubarb, every night, and a mixture three times a day, consisting of equal parts of infusion of valerian and gentian, with a saline aperient. Milk diet.

March 5th.- He has felt more comfortable since the cupping, having had less vertigo and less of the general sense of uneasiness about the head, which, however, he still says has not amounted to pain. His articulation is not improved; the tongue is still furred, and he has some thirst; bowels open. The last day or two he has had a good deal of palpitation, with a sense of anxiety about the præcordia. To omit the mixture, and take two grains of pil. hydrarg. with three of Dover's powder, night and morning.

March 8th.- His mouth is slightly affected by the mercury, and he complains much of palpitation of the heart. The urine, which is abundant, was tested for albumen, but none detected. 
The pill to be taken at night only. To have tinct. digitalis, $m x$, and tinct. hyoscyami $m x v$, in infusion of valerian, three times a day.

March 12th.- - Has less palpitation, and his head feels more comfortable, but he complains of a constant sense of craving. Pulse 92 ; bowels open ; paralytic symptoms much the same.

March 15th.-Palpitation and impulse of the heart somewhat diminished, but he has much more giddiness, and apparently from this cause, mainly, he has more difficulty in walking; his mouth is still tender; the bowels are kept well open with house medicine: Applic. emp. lyttæ nuchæ.

March 29th.- - Since the last report he has improved, both in his own feelings and in his powers of articulation and of walking; the gums are still tender, his pulse is quick, and he perspires much, especially about the head ; he complains much of the sense of sinking at the pit of the stomach, and of craving for food, and is anxious to be allowed a more generous diet. To have a little fish for dinner.

April 9th.-He continued apparently to improve till yesterday, when he was seized with a paroxysm of palpitation and dyspnœa, his speech became much more inarticulate, and paralysis, both of sensation and motion, of the right side was increased. Having laid hold of a vessel of hot water, without being aware of the temperature, he has burnt his hand. Ten leeches to be applied to the temples, to be followed to-morrow morning by a blister to the nucha. To have a jalap and calomel purge.

April 12th.- - His speech is very indistinct, but he thinks that he is again recovering power and feeling in his right hand and arm. The tongue is white and furred, and the pulse quick ; and there is some dyspnœe.

April 16th.-His speech is again improving considerably, and he has manifestly more sensation and power of motion of the right side. He thinks that the accidental burn, which has been followed by suppuration, has been of use to the paralytic limb.

April 19th.-All the paralytic symptoms are much the 
same; the tongue still furred, and the pulse quick; the skin cool and moist, and the bowels acting well.

April 21st.- He is to-day exceedingly feeble, his speech quite inarticulate, his pulse more frequent, and of much less power; his breathing is quick and hurried; his intelligence is unimpaired and he intimates that he feels very faint and exhausted; his countenance is somewhat more flushed than it has been, and expresses considerable anxiety. There are no fresh paralytic symptoms. Stimuli and an antispasmodic mixture were ordered to be taken as he might require them; mustard cataplasms to the soles of the feet.

April 24th.- - He continued in much the same state till this morning, when he suddenly uttered a cry, and made signs for the sister. On her arrival at his bedside he was unconscious, breathed twice or thrice, and expired not more than three or four minutes from the time of his cry for assistance.

Examination of the body 24 hours post mortem.

Little or no emaciation.

Head.-The arachnoid, slightly opaque, was raised over both hemispheres by clear serous effusion. The vessels of the pia mater were congested, but the substance of the brain generally was pale and rather soft. In the middle of the left corpus striatum there was a large apoplectic clot, of an uniform dark black colour, and apparently of very recent formation. The cerebral substance, for some distance round the clot, was in a softened pulpy condition, in colour presenting various shades of reddish-brown.

In the centre of the left half of the pons Varolii was a small clot of the size of a horse-bean, similar in appearance to the one in the corpus striatum, and apparently of about the same date; the surrounding cerebral substance was also in a like state of white pulpy softening, but without any of the intervening rusty discoloration. Towards the centre of the right half of the pons, the cerebral substance was also in a state of white softening. All the arteries at the base of the brain, and the smaller hranches given off from them, were loaded with atheromatous deposit.

Chest.-The left pleural cavity contained between three 
and four pints of recently extravasated blood, a considerable portion of which was coagulated. On seeking carefully for the source of the hemorrhage, there was discovered a laceration in the costal pleura, just below the head of the ninth rib. The aperture, about half an inch in length, was surrounded by a large clot of extravasated blood; on tracing this extravasation it was found to extend posteriorly from the apex to the base of the chest, and laterally half way to the cartilages of the ribs. The cellular tissue in the posterior mediastinum was throughout infiltrated with recently coagulated blood, by which the pleura on either side was raised. On laying open the aorta, in situ, there was discovered a nearly transverse rupture, three quarters of an inch in length, situated immediately beneath the origin of the subclavian artery, $i$. e. at the extreme upper part of the descending aorta. This rupture was directly through all the coats of the artery; the edges of the aperture were somewhat ragged, and traversed a patch of atheroma; the lining membrane adjoining was friable and easily separable, but was not (till the vessel had been handled) actually detached from the coat beneath.

Above the point of rupture there was no separation of the coats of the artery; but, from this point downwards, blood was effused between the coats of the vessel, splitting it up as far as the iliacs. In the upper portion of the aorta the splitting was through the substance of the middle coat, the annular fibres of which were distinctly discernible, and in almost equal abundance, on the outer and inner side. As the separation of the-coats of the vessel was traced farther and farther downwards, there was less of the middle coat on the outside, till on arriving at the bifurcation of the aorta, the effused blood was inclosed between the middle, and the outer, coat of the vessel. The quantity of blood effused between the coats of the artery varied at different points, but nowhere occupied more than three parts of the circumference of the vessel.

Throughout its entire course the aorta was thickly studded with atheromatous deposit, varying much in extent and XXXII. 
thickness; in some places augmenting very considerably the whole thickness of the middle coat, which was everywhere somewhat hypertrophied. The atheromatous patches began immediately above the aortic valves, and were scattered in small quantity along the ascending and transverse portions of the arch as far as the origin of the left carotid. From this point the artery was thickly studded throughout, as far as it and its branches were examined.

The pericardium was healthy. The heart was enormously enlarged, and weighed one pound six ounces and a half (avoirdupois). The principal enlargement was of the left ventricle, the muscular parietes of which measured one inch and one eighth, except towards the apex, where the thickness rapidly diminished, and at the point measured less than a quarter of an inch. The cavity of the ventricle was greatly enlarged. The parietes of the right ventricle were not three lines thick, but its capacity was increased to an extent corresponding with the left ventricle. The capacity of the auricles was not proportionately increased. The mitral and aortic valves presented the slightest degree possible of thickening and opacity, associated with a few minute spots of atheromatous deposit; with these exceptions all the valves were healthy, as was also the endocardial membrane throughout. The coronary arteries appeared to be perfectly healthy, there being some patches of atheroma around their orifices, but none in the arteries themselves.

The left lung was compressed by the blood effused into the pleural cavity, but was healthy in structure, as was also the right lung. In the right pleural cavity there was a considerable quantity of straw-coloured serum. The pleura was healthy.

Abdomen. The liver was enlarged, but appeared to be healthy in structure.

The kidneys were rather larger than natural, their surface smooth and regular, and the capsule readily separable; on section, they presented a pale, mottled aspect. In the right there was a single simple serous cyst, half an inch in diameter, and in the left several smaller ones. The right kidney was examined by Mr. Simon, who found some of the tubules 
impacted with old epithelial scales, the renal artery irregularly dilated, its contractile coat brittle, and its lining membrane thickened by irregular fibrinous deposits.

The spleen, stomach, pancreas, and intestines were healthy; but about the middle of the ileum there was a portion of one of the strong bristles, used by shoemakers, so firmly impacted at one extremity, into the mucous membrane, as not to be removable by any ordinary force.

I have been induced to submit the foregoing case to the consideration of the Fellows of the Royal Medical and Chirurgical Society, believing that the chain of morbid phenomena which it discloses, will, as a whole, be considered as presenting many points of interest both to the pathologist and practical physician, rather than because any one of the several important lesions is particularly rare, or that I have any novel hypothesis to offer in their explanation.

Without attempting to discuss the precise nature of that change in the arterial system which leads to the formation of atheromatous deposits, if, as I am disposed to view it, we consider it as the origin of all the subsequent structural changes, both in the heart and brain, as well as the more immediate cause of the fatal termination, the foregoing case affords a remarkable example of the vast importance of what must doubtless be considered as a constitutional cause that can produce such effects. There is no evidence that this man ever suffered from any arthritic complaint, nor did the heart present any indications of having ever been the seat of any acute inflammatory action. The endocardial membrane and the several valves were, with the trivial exception mentioned, remarkably healthy; unless, therefore, we look on the hypertrophied state of the heart as a mere coincident and an example of idiopathic hypertrophy, we are constrained to view it as a consequence of that very extensive disease of the arterial system, by which the elastic reaction of the more important vessels to the heart's impulse must have been materially impaired, if not destroyed, and thus a serious obstacle presented to the circulation of the blood, 
calling for increased exertion on the part of the central organ. But there is reason for thinking that an additional cause for increased action on the part of the heart may have existed. Although from an ordinary inspection of the aortic valves they do not present any evidence of insufficiency, yet it seems probable that the column of blood in the aorta would, in consequence of its diminished elasticity, fall back, after each systole of the ventricle, with such increased force as to produce some separation of the edges of the valves, and thus some regurgitation. The existence of a slight diastolic bruit during life would appear to favour this view, which is further strengthened by a reference to the state of the ostium aortæ, which is not increased in size proportionably to the heart or the descending portion of the aorta. (The orifice of the aorta measures an inch in diameter.)

If we refer the changes in the cerebral structure, and the consequent hemorrhage and paralytic symptoms to impaired nutrition and obstructed circulation resulting from the diseased condition of the cerebral arteries, one cannot fail to be struck with the important contrast presented in this respect by the heart, the arteries of which were healthy, and whose nutrition was so greatly augmented.

Postscript, Aug. 6, 1849. Some discussion took place after the reading of the above case as to the cause of the diastolic bruit, and it was suggested that it was produced by the depression or aneurismal dilatation, which it was thought existed at the point where the rupture occurred. I have, however, carefully examined the preparation again, without being able to satisfy myself that there was anything more than a slight depression at the spot occupied by the atheromatous patch through which the rupture recurred. And my colleague, Mr. Adams, who made the post-mortem inspection, and examined the preparation when recent with considerable care, is convinced that there was nothing which could be called an aneurismal dilatation at the point in question. 


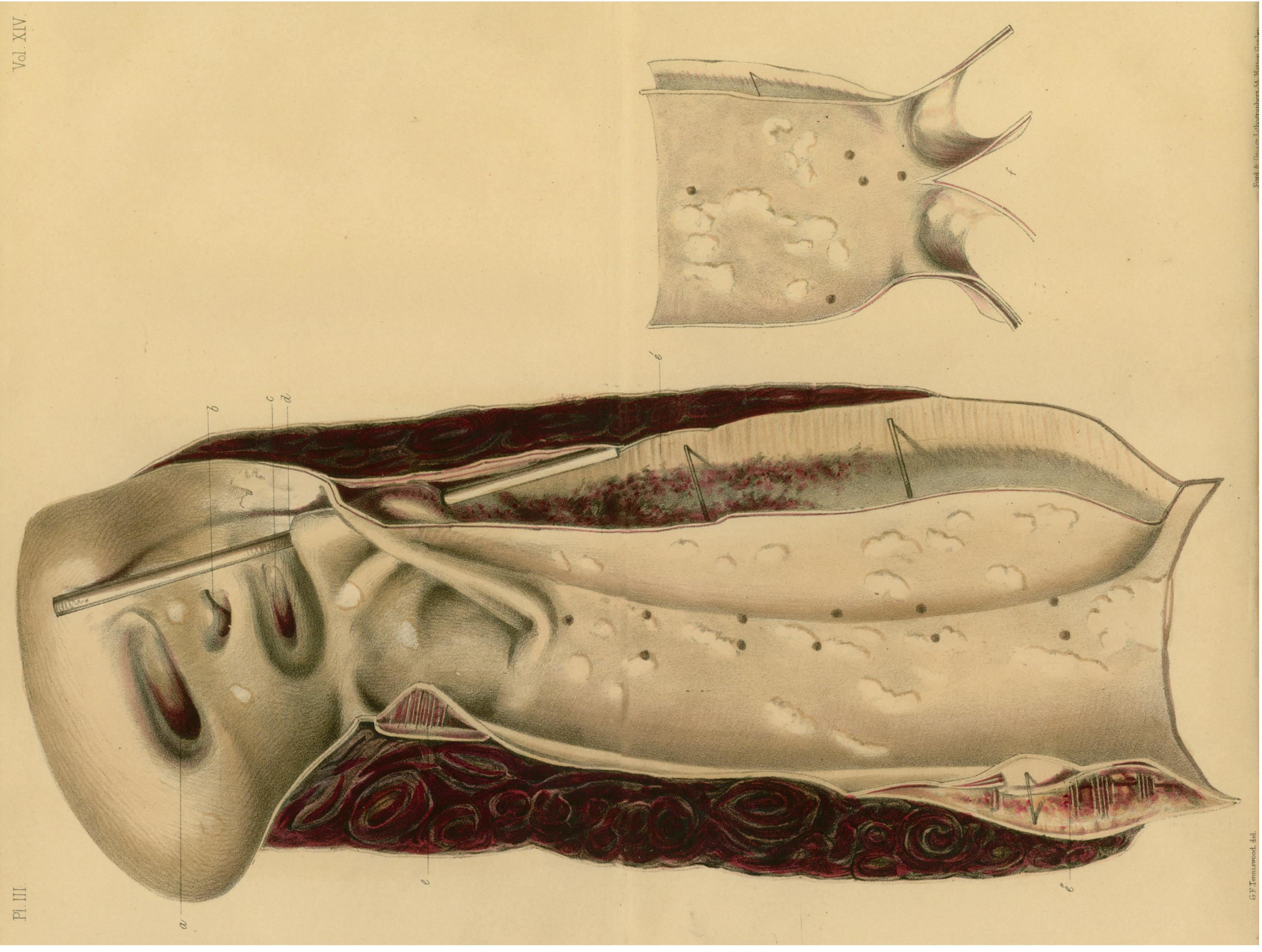




\section{DESCRIPTION OF PLATE III.}

A. Orifice of the arteria innominata.

B. Orifice of the left carotid.

C. Orifice of the left subclavian.

D. Spot at which the rupture took place, and through which a probe passes between the split middle coat of the aorta.

$\mathbf{E} \mathbf{E}^{\prime} \mathbf{E}^{\prime \prime}$. The middle coat split, showing the circular fibres, in some places stretching across from one to the other side of the artery, with the remains of the interposed coagulated blood.

F. The lower portion of the aorta, cut off, to show that the splitting of the middle coat extended to the iliacs. 